\title{
The Last Illness and Death of Hawai'i's King Kalākaua: A New Historical/Clinical Perspective
}

\author{
JOHN F. MCDERMOTT MD, ZITA CUP CHOY, \\ AND ANTHONY P. S. GUERRERO MD
}

\section{INTRODUCTION}

David La'amea Kalākaua, the last king of the nation of Hawai'i, reigned from 1874 to $1891 .{ }^{1}$ Also known as the Renaissance King, his foreign policy was two-pronged: first, to maintain the independence of Hawai'i as a nation, and second, to develop its economy, specifically through The Reciprocity Treaty with the United States. This treaty allowed Hawaiian sugar to be imported to the U.S. duty free. ${ }^{2}$ The treaty was commercially successful but became controversial in Hawai'i because of a fear that it would strengthen foreign control. Some even saw it as the first step in the annexation of the islands to

Zita Cup Choy has been affiliated with the Friends of 'Iolani Palace since 1977. In 2003 after 26 years as a volunteer docent she was hired to conduct docent training classes. Zita also provides research support to the Friends staff. She has been a volunteer docent / researcher at Washington Place since 2000.

Anthony P. S. Guerrero MD is Professor and Chair of Psychiatry and Clinical Professor of Pediatrics at the University of Hawai ‘i at Mānoa John A. Burns School of Medicine.

John F. McDermott MD is Emeritus Professor of Psychiatry at the John A Burns School of Medicine, University of Hawai $i$. He has published numerous articles and books in the scientific literature, most recently, People and Cultures of Hawaii: The Evolution of Culture and Ethnicity, with Naleen Andrade MD, Honolulu, Hawai'i University of Hawai'i Press, $2 O I I$.

The Hawaiian Journal of History, vol. 49 (2015) 
the United States. Kalākaua set out on a secret mission to renegotiate the treaty that was due to expire. But he unexpectedly became ill and died at the Palace Hotel in San Francisco on January 20, 1891. ${ }^{3}$ The cause of death given was Bright's ${ }^{4}$ disease, a chronic condition of the kidneys. ${ }^{5}$

Questions have been raised about Kalākaua's death, including why he died so unexpectedly in a hotel far away from home, from a chronic illness it was known that he had. This study will reexamine that illness and his death. ${ }^{6}$

After searching and finding no further published investigation of the death, we chose to apply a method called the Historical Clinicopathological Conference. ${ }^{7}$ Its aim is to review the circumstances of Kalākaua's last illness and death, and, using modern medical knowledge, to achieve a better understanding of it.

\section{The STUdy}

The traditional Clinicopathological Conference (CPC) is a regular hospital conference for the medical staff led by a senior staff physician, focused on the better understanding of a patient's death. The format involves a presentation of the case by a staff physician, including the laboratory and other tests, followed by presentation of the autopsy findings by a pathologist. It concludes with an expert led discussion to arrive at consensus about the final cause of death.

The Historical CPC follows the same outline, but concerns some well-known historical figure (such as Wolfgang Amadeus Mozart or Edgar Allen Poe) whose cause of death was uncertain. It really represents a kind of medical detective work, using current medical knowledge to fit the various pieces together. One might think of it like trying to work with a jigsaw puzzle to form a picture, even though some pieces are missing. For example, with the Historical CPC there are usually no blood tests or x-rays nor autopsy findings to consider.

Our Kalākaua Historical CPC will follow the same standard format used in an actual hospital CPC: first, the deceased's past personal and medical history; next, the course of his last illness; then, the cause of death as determined at the time. Second, we will review and update the cause of death, using current medical knowledge about his diagnosis and treatment. Third, we will consider some implications from 
the point of view of historical epidemiology, i.e., the prevalence and distribution of diseases at the time. ${ }^{8}$

First, however, we should consider the limitations to this study. Kalākaua's personal medical history is incomplete. He had good medical care from doctors at Queen's Hospital, but his name is not found in any of the patient archives. We found a detailed report by the attending physician who was at his bedside during his final illness, a senior U.S. Naval surgeon named George W. Woods. This report revealed data not previously published, including a partial autopsy. ${ }^{9}$

\section{Historical BACKGROUND}

Hawai' $\mathrm{i}$ is the most remote group of islands in the world..$^{10}$ For centuries before Western contact, this isolation served as a mixed blessing for the ancient Hawaiians. On the one hand, it kept global diseases at bay, e.g., the black plague that so devastated Europe. On the other hand, it contributed to the evolution of a community with little or no inborn immunity to other diseases such as measles and smallpox. After Western contact, this lack of immunity would lead to widespread epidemics, decimating the Hawaiian population in the nineteenth century. ${ }^{11}$ Population estimates for the late 1770 's range from 240,000 to 400,000 . A census taken in $18_{3} 6$, the year Kalākaua was born placed the Native Hawaiian population at $108,579 \cdot{ }^{12}$ Population estimates have long been controversial. In 1874 the Pacific Commercial Advertiser addressed the issue stating:

Captain Cook's estimate (400,00o) has been supposed to be too large, but if the ratio of decrease from 1779 to 1832 (when the first official census was taken) was as great as from 1832 to 1872 , in proportion to the number of years and inhabitants, it was remarkably correct; but when we consider the numerous wars of the first period, and the fatal pestilence about the commencement of the present century, it $(400,000)$ would seem an under estimate. ${ }^{13}$

\section{KalĀkaua's Personal History}

David Kalākaua was born in 1836 , one of seven children of High Chief Kapa'akea and High Chiefess Keohokālole. ${ }^{14}$ According to Hawaiian custom, he was given as hānai (adopted by another high chiefess) 
in infancy, and at three-and-a-half years was enrolled in the Chiefs' Children's School, a boarding school for children of high ranking chiefs. ${ }^{15}$ At age four he was taken to visit his grandfather on the morning of his execution, ${ }^{16}$ who had been convicted of poisoning his wife. ${ }^{17}$ After finishing his schooling, David Kalākaua studied law, was admitted to the $\operatorname{bar}^{18}$ and held a number of government positions until he was elected to become Hawai'i's seventh king in 1874 .

Kalākaua was married to Julia Kapi'olani for almost thirty years. ${ }^{19}$ They had no children. The infertility may have been his, as Kapi'olani had had a pregnancy in a previous marriage. ${ }^{20}$ As for personal habits, Kalākaua smoked cigars and a pipe, gambled, and enjoyed fine wines and whiskey, earning him the dubious title of the "Merrie Monarch."

Early in his reign, Kalākaua travelled to Washington D.C. to facilitate the proposed Reciprocity Treaty. He was the first head of state to visit the United States ${ }^{21}$ and to appear before the U.S. Congress. ${ }^{22}$ In 1881 , he travelled around the world, visiting seventeen countries in ten months, looking for possible immigrant populations to supplement the declining Hawaiian population. ${ }^{23}$ Throughout his reign, Kalākaua promoted new technology and international relations for the Kingdom. In spite of this, there was increasing political unrest. The king signed the 1887 constitution, known as the Bayonet Constitution, under duress. It was a revision limiting the power of the king and the voting rights of Native Hawaiians. ${ }^{24}$ Tensions continued to build. Unless terms for extension could be mutually agreed upon by the nation of Hawai'i and the United States, the Reciprocity Treaty was due to expire in 1891 . Kalākaua chose to go to the United States to do this himself in December 1890 . His trip was disguised as a "health" visit to restore his energy from fatigue from work. ${ }^{25}$ The flagship of the U.S. Pacific fleet was put at his disposal for the trip to California.

\section{History OF KALĀKAUA's LAST IlLness}

Soon after his arrival, King Kalākaua, invigorated by the cooler weather, embarked on a trip through southern California with a heavy social schedule and numerous public appearances. ${ }^{26}$

Along the way he developed a cold that turned into 'bilious fever' (fever accompanied by nausea, vomiting and diarrhea) followed by 
unusual fatigue, an alarming intermittent right-sided paralysis and some difficulty with his speech. He was treated by a local medical doctor and accompanied back to San Francisco to his suite at the Palace Hotel on January 7, 1891. Becoming no better after several days, he was placed under the care of U.S. Navy Medical Inspector George W. Woods. From then on, Dr. Woods was at his bedside throughout the last illness. He kept meticulous notes that are that basis of a report addressed to John Cummins, Minister of Foreign Affairs of the Kingdom of Hawai'i. Dr. Woods wrote this report as he accompanied his patient's body back to Hawai'i.

\section{KalĀKaUA's Past Medical History}

King Kalākaua led a very active life and had access to good medical care. The names of his physicians are known and they practiced at the Queen's Hospital in Honolulu. There are no records of Kalākaua as a patient to be found in the archives there. He seems to have been free of major illnesses for most of his life. He did suffer from occasional colds, and the only medication we know that he took was Chlordyne, a well-known nineteenth-century patent medicine. He circled the globe in 1881 and diaries reveal no mention of illness, though he would have been exposed to numerous unfamiliar germs during that tenmonth period.

The year before his trip to California, Kalākaua was noted to fall asleep at odd times and was diagnosed with Bright's disease. ${ }^{27}$

\section{The Course of KalĀKaUA's Last Illness}

On January 13 Dr. George W. Woods, assumed responsibility for King Kalākaua's care. Dr. Woods faithfully recorded his patient's changing condition during the following week as he lapsed in and out of consciousness. His patient's vital signs gradually rose abnormally (these were temperature, pulse and respirations only-the means for routine measurement of blood pressure was not yet available). Of most concern was his meager urinary output, an advanced symptom of the previously diagnosed Bright's disease. This meant that toxic waste products, instead of being excreted in the urine, were building up in his system, poisoning it. 
During this time, Dr. Woods consulted two eminent San Francisco specialists, and together they decided to flush the system of toxins. Administration of diuretics and cathartics afforded some improvement, but with the kidneys so damaged it could only be temporary relief.

The king's downhill course continued, with increasing difficulty breathing and increasing heart rate. His fever spiked between $10^{\circ}$ and $104^{\circ}$; his cold hands and feet suggested that his circulation was becoming more compromised and his heart was failing. Irritation of the brain by toxins was suggested by intermittent right-sided paralysis and convulsions. Kalākaua experienced increasing difficulty in breathing and swallowing.

With words appropriate for a king, Dr. Woods pronounced Kalākaua dead:

"At 2:35 pm on Tuesday, January 20, 1891, His Majesty, King Kalakaua I of the Kingdom of Hawai “i, ceased to exist." ${ }^{28}$ His final diagnosis was "Bright's Disease with Uremic Blood Poisoning."

The body was embalmed, dressed in a plain black suit, and returned to Hawai'i aboard the flagship of the U.S. Pacific fleet, accompanied by Dr. Woods.

\section{The Historical CPC: Cause of Death Reconsidered}

\section{Using Today's Medical KNOWLEdge}

Bright's Disease was a valid medical diagnosis in 1891 but is no longer used, as it is too broad. Its main contribution to the medical community in the nineteenth century was to distinguish kidney disease from heart disease so that they could be treated separately.

Today we would likely update the cause of death from Bright's Disease with Uremic Blood Poisoning, to End Stage Renal Disease with Metabolic Encephalopathy. The new term, End Stage Renal Disease (ESRD), simply means that the disease was in the last of five stages, ranging from mild ( 1 ) to kidney failure (5). In this way, appropriate treatment can be prescribed at different stages, e.g., kidney dialysis in advanced stages. The additional secondary term Dr. Woods used in his diagnosis, Uremic Blood Poisoning would be changed today to Metabolic Encephalopathy. This term indicates that the toxic build up in the system was even more specific and significant. In other words, the 
poisoning was affecting the brain itself, accounting for the intermittent paralysis, convulsions, lapses of consciousness and eventual coma.

In updating the diagnosis to ESRD with Metabolic Encephalopathy, we are simply expanding on its specific effects and putting it into a modern medical framework.

\section{A Partial Autopsy Changes the Diagnosis}

There are some additional findings to consider today. After the king was pronounced dead, he was embalmed. While the body was opened for that purpose, Dr. Woods, who supervised the process, took the opportunity to inspect the internal organs that were exposed. He termed his observations "a partial autopsy." They can be found buried in his report to Minister Cummins, but he did not use them in establishing his diagnosis. Nor were they published in the press, either then or later.

The essential observations he made during the embalming process were: (our words in brackets) "the heart greatly hypertrophied [enlarged], ... evidence of slight pericarditis [a film forming around the heart], ... the aorta [main artery in the body] and its branches atheromatous [filled with cholesterol plaques],... the liver contracted, distinctly cirrhotic [scarred],... [but] "no effusions were found in the [body] cavities." To explain further, the finding of no effusions is a negative finding, meaning there was no backup and fluid accumulation in the body cavities we would expect from severely obstructed organ function and blood flow.

What more do these observations tell us about Kalākaua's final illness and death? They suggest that besides the kidneys, two other major organs, the liver and the heart, were both diseased and most likely contributed to his death, overlapping the kidney failure and leading to his rapid decline and unexpected death.

First the liver: it is notable that liver cirrhosis was observed to be clearly present, yet there were no effusions (fluid) evident in the abdominal cavity. This suggests that cirrhosis was a contributing, but not a principal, cause of death. If there had been liver failure, there would have been fluid buildup (effusions) within the body cavity, and jaundice—or yellowing of the skin—observed externally, as associated findings. 
As to the cause of the cirrhosis, in America, the most common cause at that time was excessive alcohol intake. But in Europe the most common cause was the result of hepatitis. ${ }^{29}$ Which did Kalākaua suffer from? Probably it was excessive alcohol intake, considering his fondness for strong drink. But there were no known episodes of blackouts or withdrawal symptoms from alcohol in his medical history, so that from these findings alone, one can conclude that cirrhosis was not the primary cause of death.

Next, consider the heart. Certainly it was acutely exhausted. It had been pumping harder and harder to keep the circulation going against the resistance of plaque-filled arteries and chronically diseased kidneys. Yet Dr. Woods described it quite specifically, as greatly hypertrophied. That is a term that means more than simple recent enlargement from overwork. Rather, it is usually evidence of longstanding high blood pressure and hypertensive cardiovascular disease. So, while blood pressure was not routinely recorded as a vital sign in those days, we are able to see the consequences of longstanding elevated blood pressure on the heart at autopsy, e.g., the heart was described as greatly hypertrophied. The slight film around the heart, on the other hand, may have been related to the diagnosed kidney disease and the toxic poisons, i.e., the uremia diagnosed by Dr. Woods. If the pericarditis had had time to develop further, it could have served as a factor in Kalākaua's death by constricting the heart.

So in addition to kidney failure, we may conclude from the additional autopsy findings that there was probably an interaction among three diseased organs, kidney, liver, and heart. This interaction acted as the proverbial "perfect storm," leading to Kalākaua's rapid decline. Indeed, an interaction with the heart may have been as important as kidney failure in causing his death. An example of this overlapping interaction of kidney with heart can often be seen in the buildup of toxins in the blood from the failure of the kidneys to function. These toxins then have a critical effect on the heart itself. Potassium, for instance, is a chemical essential in small amounts for rhythmic heart activity, i.e., for life itself. But potassium can become poisonous to the same heart that needs it to function normally. Excessive potassium buildup after loss of the kidneys' excretory function leads to disturbed rhythms and cardiac arrest. This buildup of potassium, known by the 
medical term hyperkalemia, may have stopped (arrested) Kalākaua's heart, which was already failing from overwork.

So Dr. Woods' diagnosis: "Bright's Disease with Uremic Blood Poisoning," was accurate as far as it went in 1891 , but today is not specific or inclusive enough. If we were to modify it, we would expand it to reflect a multiple organ failure: i.e., End Stage Renal Disease (ESRD) with Metabolic Encephalopathy, as well as Longstanding Hypertensive Cardiovascular Disease, and Cirrhosis of the Liver.

We may wonder why Dr. Woods, the one who made these key additional post mortem observations of the two other internal organs, failed to connect the dots among them. There are two readily apparent reasons: 1) the level of medical knowledge at the time was in an early phase of development. Medicine was focused on separating the functions of the major organs in order to treat them individually, and not until much later toward an understanding of the interaction among them. 2) Dr. Woods states in his report that a complete autopsy had been 'opposed.' Thus it would have been improper, if not illegal, for him to use information from what he termed a "partial autopsy" to add to the diagnosis of kidney disease as the cause of Kalākaua's death.

\section{Applying Today's Medical Knowledge to His Care}

How might today's modern medical treatment have interrupted, or perhaps even prevented, the condition or conditions that led to Kalākaua's premature death at the age of fifty-four?

First, Kalākaua's ESRD (or fatal kidney disease) could likely have been relieved today by placing him on kidney dialysis to save his life, with later consideration of kidney transplant for the longer term. Furthermore, he would have been placed on medication to reverse incipient heart failure.

But earlier preventive care would have been just as important: Today, anti-hypertensive, or blood pressure-lowering medication would have been employed over the intervening years, had measurement of high blood pressure been available to his doctors at the Queen's Hospital. That would have reduced the chronic strain on the heart that led to its observed "greatly hypertrophied" state. Indeed, if part of his kidney disease were a (common) consequence of pro- 
longed hypertension, medication could have prevented the former. Modern day counseling for dietary change, including alcohol consumption, as well as control of smoking, would have been offered early, in hopes of preventing both arteriosclerosis and liver cirrhosis.

\section{CONSIDERATION OF OTHER POSSIBILITIES}

There had been rumors for some time about assassination from poisoning, so that some discussion of its possibility seems indicated. ${ }^{30}$

Among the most common poisons in use at the time were arsenic and lead. Arsenic, commonly a component of patent medicines, in large quantities produces muscle cramps, numbness and weakness of the limbs, as well as a characteristic dark pigmentation and thickening of the skin. Furthermore, arsenic does not affect the kidneys, so it would not have been central to his death.

Lead poisoning, on the other hand, typically is marked by abdominal pain and weight loss, as well as characteristic neurological and/or behavioral signs. These include significant memory loss and decreased concentration, as well as numbness and muscle weakness of the arms and legs, and/or tremor or trembling of the hands.

None of these signs of arsenic or lead poisoning were noted by Dr. Woods, who examined the King physically on a daily basis during his last illness, as well as post mortem.

There are other disease possibilities. In the face of protein in the urine, or proteinuria, one of the likely ones for which Kalākaua could have been at risk is immune-mediated or autoimmune diseases. These are conditions in which the body produces antibodies to fight a disease, but they either directly attack or collaterally damage the person's own healthy tissue instead.

One intriguing possibility is an immune condition related to a streptococcal infection (specifically, group A $\beta$-hemolytic streptococcus), which causes the common "strep throat" as well as-via immune system reactions-other more serious conditions, including rheumatic fever, which was a common killer in Hawai' $i$ of the 1800 ; and post-streptococcal glomerulonephritis, which may have been-based on an epidemiological analysis-the cause of death for Wolfgang Amadeus Mozart in 1 $791 .^{31}$

This is how such immune system reactions happen: One or two 
weeks after recovery from a specific form of strep throat infection, individuals who are vulnerable develop acute rheumatic fever, in which the body's antibodies produced against the strep germ attack the heart and the joints.

Kalākaua's kidney disease could have been the result of a chronic post streptococcal glomerulonephritis. Post-streptococcal glomerulonephritis develops when antibodies from either a strep throat or a strep skin infection (impetigo) deposit in the kidneys and cause damage. Why do we suggest this as a possibility? There appears to have been a family history of immune disorders related to streptococcal infections. Both his younger brother, Prince Leleiohoku, ${ }^{32}$ and his niece, Princess Victoria Ka'iulani, ${ }^{33}$ were reported to have died in their twenties of rheumatic fever, affecting the heart in the former, and the joints in the latter. ${ }^{34}$ Such a strong family history of susceptibility found in both first and second degree relatives, combined with another factor, their Polynesian blood, would put Kalākaua at risk for streptococcal infections and their consequences. Recent research studies in Hawai'i and across the Pacific, reveal that individuals with fifty percent or greater Polynesian blood are several times more vulnerable to Group A strep induced acute rheumatic fever than the rest of the population. ${ }^{35}$ Today, this known vulnerability to immune-mediated diseases is partly managed by prompt antibiotic therapy against the Group A strep infection in the acute phase to abort the immunemediated reaction, followed up with close monitoring and protection from future infections. On a global level, and in developed (but not necessarily developing) nations, there appears to have been a decline in both rheumatic fever and post-streptococcal glomerulonephritis in the last half century. ${ }^{36}$

But even in modern-day Hawai'i there still appears to be a disproportionately high risk for streptococcal-related infections among Hawaiians and other Polynesians. Why this increased risk? The answers lie in epidemiology, the scientific study of prevalence as well as the causes and effects of disease in specific populations. The late Dr. O. A. Bushnell, professor of microbiology and medical history at the University of Hawai ' $i,{ }^{37}$ was a scientist who looked beyond the statistics, beyond the number count of Hawaiians who died in the raging epidemics of the nineteenth century. He was trying to understand the continued vulnerability of Native Hawaiians. Why, he won- 
dered, did they remain so vulnerable? Why didn't they develop immunity as time passed?

As a result of his studies, Bushnell proposed an evolutionary mechanism called Genetic Drift, explaining their increased vulnerability to disease over time due to slowly lowered immunity. He suggested that in an isolated population such as the early Hawaiians, the lack of genetic diversity results in not just in biologically mediated protective factors enhanced over time, but also vulnerabilities simmering just beneath the surface. Some can be deadly, i.e., slowly lowering the capacity to develop immune response to disease. They are deadly because this weakening of the immune system's capacity to produce antibodies to newly introduced disease would go long unnoticed. Until, that is, it was challenged by the introduction of new diseases into the environment and found unable to respond. That is how a childhood disease such as measles can erupt into a raging epidemic throughout the adult population. They included among their victims persons of royal blood, such as the king's brother, Leleiohoku, who died of acute rheumatic fever in his twenties. Royal blood conferred no special protection-then, or in any century.

\section{Conclusion}

The king died wishing he could have done more for his people. From our CPC, it appears that King Kalākaua was affected by medical conditions that resulted from conditions that may have affected Native Hawaiians as disproportionately in the 1800 as they still do today (e.g., possibly streptococcal-related kidney conditions) as well as a Western-introduced lifestyle (e.g., alcohol as the cause of liver cirrhosis and tobacco as the cause of atherosclerotic heart disease). It is the authors' hope that, through the careful study of the king's death, we can learn more about the complex interplays of illnesses that that continue to adversely affect the people of Hawai'i.

\section{Notes}

The authors would like to thank 'Iolani Palace for its ongoing support and Philip A Mackowiack MD of the University of Maryland for his consultation on the Historical Clinicopathological Conference. 
The authors would also like to acknowledge the kind assistance of Tiffinie Kiyota in the preparation of this manuscript.

${ }^{1}$ Richard Wisniewski, Rise and Fall of the Hawaiian Kingdom (Honolulu: Pacific Basin Enterprises, 1979) 112.

${ }^{2}$ Helena Allen, Kalakaua Renaissance King (Honolulu: Mutual Publishing 1994) 63

${ }^{3}$ Hawaiian Almanac and Annual for 1886 Thomas G. Thrum, Publisher: (Press Publishing Company, 1886) 6.

${ }^{4}$ Bright's disease was named after an English physician, Dr. Richard Bright, who, in the early nineteenth century, identified kidney disease by a simple test, by heating a spoonful of urine over a lighted candle. Albumin is a protein normally found in the blood, and is re-circulated into the bloodstream by the kidneys after they have filtered out the waste products. If kidney function is impaired by disease, some may spill over into the urine.

${ }^{5} H G$, February 3, $1891,2: 1$.

${ }^{6}$ This study began as an attempt to update and refine answers to questions about Kalākaua's death from visitors to 'Iolani Palace, where Dr. McDermott has served as a docent and Ms. Cup Choy is Historian / Docent Educator.

7 Philip A Mackowiack MD, Post Mortem: Solving History's Great Medical Mysteries (Philadelphia: American College of Physicians, 2007).

${ }^{8}$ In the process of developing this study, we used several expert consultants who volunteered to review the data with us, among them a professor of medicine at the University of Maryland who has developed this historical method, as well as a senior cardiologist at the University of Hawai' $i$, and a medical geneticist at Tulane University.

${ }^{9}$ George W. Woods, Report to John A. Cummins, Minister of Foreign Affairs, Last Illness and Death of King Kalākaua, FO \& Ex, AH.

${ }^{10}$ Andrew Lind, Hawaii's People: A Land of Many Islands (Honolulu: University of Hawaii Press 1955) 1.

${ }^{11}$ Eleanor C. Nordyke, The Peopling of Hawai'i (Honolulu, University Press of Hawaii, 1977) 14 .

${ }^{12}$ Nordyke, 14-5

${ }_{13}$ PCA February 14, 1874 3:7.

${ }^{14}$ Liliuokalani, Hawaii's Story by Hawaii's Queen, online edition 399.

${ }_{15}$ Amos Starr and Juliette Montague Cooke, Their Autobiographies gleaned from their Journals and Letters (Honolulu: The Daughters of Hawaii 1987) 389-9o.

${ }^{16}$ Mary A. Richards, The Hawaiian Chiefs' Children's School I839-I850, (Rutland, Vermont: Charles E Tuttle Company, 1970) 85-86.

17 Richards, The Hawaiian Chiefs' Children's School I 839-I850, 84 .

${ }_{18}$ PCA February 5, 1870 3:4.

${ }^{19}$ EB June 24, 1899, 1:4

${ }^{20}$ Maili Yardley and Miriam Rogers, Queen Kapiolani, (Honolulu: Topgallant Publishing 1985) 1.

${ }^{21} \mathrm{http}: / /$ history.state.gov/departmenthistory/visits/hawaii

${ }^{22}$ http://history.house.gov/Institution/Joint-Sessions/40-59/ 


\section{2}

23 New York Times July 20, 1881.

${ }^{24}$ Wisniewski, Rise and Fall, $83-84$.

${ }^{25} H G$ December 3o, 1890 4:4.

${ }^{26} H G$, February 3, 1891 2:1.

27 Boston Evening Transcript January 20, 1891.

28 Woods, Last Illness and Death of King Kalakaua.

${ }^{29}$ Personal communication to one of the authors from a consulting MD.

${ }^{30}$ Allen, 211.

${ }^{31}$ RH Zegers, A Weig, A Steptoe, The death of Wolfgang Amadeus Mozart: an epidemiologic perspective. (Annals of Internal Medicine 2009 Aug 18;1 $5^{1}$ (4)) 274-8, W96-7.

32 HG April 11,1877 2.2.

33 New York Times March 19, 1899.

${ }^{34}$ Kristin Zambuka, Kalakaua, Hawaii's Last King (Honolulu: Mana Publishing 2002) 26.

${ }^{35}$ DK Kurahara, et al, Ethnic Differences in developing rheumatic fever in a low income group living in Hawai 'i, (Ethnic Disease 2006 Spring: 16 (2) 357-61.

${ }^{36}$ Stewart J. Jackson, Andrew C. Steer, Harry Campbell, Systematic Review: Estimation of global burden of non-suppurative sequelae of upper respiratory tract infection: rheumatic fever and post-streptococcal glomerulonephritis. (Tropical Medicine and International Health, 16 (2011)) 2-11.

37 O A Bushnell, The Gifts of Civilization: Germs and Genocide in Hawaii (Honolulu: University of Hawaii Press 1993) 59. 